\title{
KẾT QUẢ PHẪU THUẬT TIM Hở ÍT XÂM LẤN VÁ THÔNG LIÊN THÁT QUA ĐƯờnG NGỰC PHẢI Ở TRẺ EM TẠI TRUNG TÂM TIM MẠCH - BỆNH VIỆN E
}

\section{Trần Thiện Đạt ${ }^{1^{*}}$, Đố Anh Tiến ${ }^{2}$, Lê Ngọc Thành ${ }^{2}$, Nguyễn Bá Phong ${ }^{2}$, Lê Ngọc Minh ${ }^{2}$}

\section{TÓM TẮT}

Muc tiêu: Nhận xét chỉ định, một số đặc điểm kỹ thuật và kết quả sớm của phẫu thuật tim hở ít xâm lấn vá thông liên thất (TLT) qua đường ngực phải tại trung tâm tim mạch bệnh viện $\mathrm{E}$ (TTTM-BVE).

Phương pháp: Nghiên cứu mô tả, tiến cứu kết hợp hồi cứu trên 106 bệnh nhân $(\mathrm{BN})$ được chẩn đoán TLT và phẫu thuật ít xâm lấn qua đường ngực phải tại TTTM - BVE từ tháng 6/2018 đến tháng 12/2020.

Kết quả: 106 bệnh nhân có đủ tiêu chuẩn nghiên cứu. Tuổi trung bình là $1,1 \pm 1,7$ tuổi, cân nặng trung bình là $7,6 \pm 4,1 \mathrm{~kg}$, tỉ lệ $\mathrm{Nam} / \mathrm{nữ}$ là 1,3. Trong đó 102 bệnh nhân $(96,2 \%)$ suy tim I,II trước mổ. Kích thước lỗ thông trung bình 7,2 \pm 2,4 mm (3-15 mm), trong đó quanh màng chiếm $67 \%$, phần phễu $28,3 \%$, buồng nhận $2,8 \%$ và cơ bè $1,9 \%$. Thời gian chạy tuần hoàn ngoài cơ thể là $70,2 \pm 28$ phút, cặp ĐMC trung bình $45,7 \pm 26$ phút và kích thước rạch da $4,18 \pm 0,5 \mathrm{~cm}$. Thời gian thở máy sau mổ là 15,7 $\pm 10,8$ giờ, thời gian nằm hồi sức $3,3 \pm 1,1$ ngày và thời gian nằm viện $12,4 \pm 5,1$ ngày. Tồn lưu sau mổ chiếm $5,7 \%$. Khám lại 3-12 tháng có 94,6\% NYHA I, 89,1\% ALĐMP về bình thường và có $95,7 \%$ bệnh nhân hài lòng về phương pháp này.

Kết luận: Phẫu thuật ít xâm lấn vá TLT qua đường mở ngực phải ở trẻ em cho kết quả hết sức khả quan, đem lại nhiều lợi ích cho người bệnh như: hồi phục nhanh, giảm nguy cơ nhiễm trùng xương ức, tính thẩm mỹ cao với sẹo mổ nhỏ...Hầu hết bệnh nhân rất hài lòng về phẫu thuật này.
Tù khóa: thông liên thất, phẫu thuật tim hở ít xâm lấn, 102 bệnh nhân, Trung tâm Tim mạch - Bệnh viện E

\section{SUMMARY}

\section{OUTCOME OF MINIMALLY INVASIVE VENTRICAL SEPTAL DEFECT SURGICAL CLOSURE THROUGH RIGHT ANTEROLATERAL THORACOTOMY IN CHILDREN AT THE CARDIOVASCULAR CENTER OF E HOSPITAL}

\section{ABSTRACT}

Objectives: To evaluate indications, techniques and early outcomes of minimally invasive ventrical septal defect (VSD) surgical closure via right anterolateral thoracotomy at the cardiovascular center of E hospital.

Methods: This is a prospective and retrospective descriptive type of study. 106 patients were diagnosed with VSD and underwent the minimally intensive operation through right anterolateral thoracotomy at the cardiovascular center of E hospital from June 2018 to March 2021.

Results: 106 patients in the study, mean age was $1,1+1,7$ years, mean body weight was $7,6 \pm$ 4,1 $\mathrm{kg}$, the boy:girl ratio was 1,3. 102 patients $(96,2 \%)$ were suffered from grade I, II heart failure before undergoing surgical repair. The mean VSD diameter was 7,2 $\pm 2,4 \mathrm{~mm} \quad(3-15 \mathrm{~mm})$. Perimembranous septum, infundibular septum,

\footnotetext{
${ }^{1}$ Bệnh viện Phu sản - Nhi Đà Nã̃ng

${ }^{2}$ Trung tâm Tim mạch - Bệnh viện E, Trường Đại Học Y, ĐH Quốc Gia Hà Nội

*Tác giả liên hệ: Trần Thiện Đạt; $\quad$ Email: Thiendat309@gmail.com Ngày nhận bài: 30/08/2021 Ngày cho phép đăng: 30/09/2021
} 
inlet septum and trabecular septum accounted for $68 \%, 28,3 \%, 2,8 \%$ and $1,9 \%$, respectively. The duration of cardiopulmonary bypass was 70,2 \pm 28 minutes, the aortic cross-clamping time was $45,7 \pm$ 26 minutes, the length of skin incision was $4,18 \pm$ $0,5 \mathrm{~cm}$. Postoperative mechanical ventilation time was $15,7 \pm 10,8$ hours, the duration of intensive care was 3,3 $\pm 1,1$ days and length of hospital stay was $12,4 \pm 5,1$ days. Postoperative residual shunt accounted for 5,7\%. Follow- up examination after the surgery from 3 to 12 months observed $94,6 \%$ NYHA I, $89,1 \%$ of these patients having normal pulmonary artery pressure and $95,7 \%$ of these patients satisfied results of this method.

Conclusion: Repair of ventricular septal defect through right anterolateral thoracotomy provided children with considerable results and significant benefits including early recovery, declining the risk of sternal wound infection, favorable cosmetic results with small surgical scars... The majority of the patients completely satisfied the type of operation.

Key word: ventricular septal defect, minimally invasive open heart surgery, 102 patients, Cardiovascular Center - E hospital

\section{I. ĐẶT VẤN ĐỀ}

TLT là dị tật TBS hay gặp nhất ở trẻ còn bú và trẻ nhỏ. Tần xuất TLT đơn thuần thay đổi từ 1$7 \%$ số trẻ ra đời còn sống, chiếm khoảng 20-30\% tổng số bệnh TBS ở trẻ em [1]. Hậu quả của TLT: một trong những nguyên nhân hàng đầu của suy tim ứ huyết và bội nhiễm phổi, có thể gây tử vong ở tuổi sơ sinh; viêm nội tâm mạc nhiễm khuẩn, bệnh lý mạch máu phổi tắc nghẽn... [2] Cùng với sự phát tiến bộ của khoa học, can thiệp mạch bít dù đã mở ra hướng đi mới trong điều trị TLT. Tuy nhiên phẫu thuật tim hở vẫn là phương pháp kinh điển điều trị bệnh TLT ở trẻ em.
Đường mổ kinh điển là mở dọc xương giữa xương ức với ưu điểm phẫu trường rộng thuận lợi cho các thao tác cũng như phẫu thuật các dị tật kèm theo trong tim. Ngoài ra các đường mở ít xâm lấn cũng được áp dụng: mở thấp $1 / 3$ dưới xương ức, mở ngực phải, mở cạnh ức...[3]ư Phương pháp phẫu thuật vá TLT ít xâm lấn qua đường ngực phải được triển khai và áp dụng đã cho thấy kết quả hết sức khả quan, mang lại nhiều lợi ích cho người bệnh như: hồi phục nhanh, giảm nguy cơ nhiễm trùng, thẩm mỹ với sẹo mổ nhỏ. Do đó chúng tôi tiến hành nghiên cứu nhằm đánh giá chỉ định và kỹ thuật cũng như kết quả sớm của phương pháp này.

\section{II. ĐỐI TƯợNG VÀ PHƯƠNG PHÁP NGHIÊN CÚU}

Phương pháp nghiên cúu: Nghiên cứu mô tả cắt ngang, bao gồm hồi cứu và tiến cứu. Trẻ em $\leq 15$ tuổi được phẫu thuật vá TLT ít xâm lấn qua đường ngực phải từ $6 / 2018$ đến hết 2020.

Tiêu chuẩn lựa chọn: tất cả bệnh nhân $\leq 15$ tuổi được phẫu thuật TLT ít xâm lấn qua đường ngực phải. Có đầy đủ hồ sơ bệnh án và bệnh nhân, gia đình đồng ý tham gia nghiên cứu. Tiêu chuẩn loại trừ: bệnh nhân TLT được phẫu thuật kinh điển hoặc đường mổ khác, không đầy đủ hồ sơ, thông tin bệnh án.

Các biến số dụ kiến: tuổi, giới tính. Đặc điểm lâm sàng, siêu âm trước mổ. Trong mổ gồm thơi gian tuần hoàn ngoài cơ thể, thời gian cặp $\mathrm{ĐMC}$, thời gian rút $\mathrm{NKQ}$, thời gian nằm viện. Các biến chứng sau mổ, đánh giá sau mổ qua lâm sàng, siêu âm và kết quả khám lại.

Xủ lý số liệu: số liệu được thu nhập, quản lý và xử lý bằng các thuật toán thống kê y học với phần mềm SPSS 25.0 


\section{KẾT QUẢ}

3.1. Đặc điểm chung: Trong thời gian từ $6 / 2018$ đến hết 2020 có 106 trường hợp được phẫu thuật với cân nặng trung bình 7,6 $\pm 4,1 \mathrm{~kg}(2,8-28 \mathrm{~kg})$, độ tuổi trung bình $1,1 \pm 1,7$ tuổi. Tỉ lệ Nam/ nữ là 1,3 .

\section{2. Đặc điểm lâm sàng, cận lâm sàng}

Bảng 1: Đặc điểm lâm sàng trước phẫu thuật

\begin{tabular}{|l|l|c|c|}
\hline \multicolumn{2}{|c|}{ Đặc điểm lâm sàng } & n & \% \\
\hline \multirow{4}{*}{ Triệu chứng lâm sàng } & Khó thở & 12 & 11,3 \\
\cline { 2 - 4 } & Chậm tăng cân & 58 & 54,7 \\
\cline { 2 - 4 } & Bú kém, vã mồ hôi & 19 & 17,9 \\
\cline { 2 - 4 } & Viêm phổi tái diễn & 25 & 23,6 \\
\cline { 2 - 4 } & Phát hiện tình cờ & 61 & 57,5 \\
\hline Mức độ suy tim & Độ I-II & 102 & 96,2 \\
\cline { 2 - 5 } & Độ III & \multicolumn{2}{|c|}{$-2,1 \pm 3,02$} \\
\hline Tình trạng suy dinh dưỡng & Z-score cân nặng & \multicolumn{2}{|c|}{$54,7 \%$} \\
\cline { 2 - 4 } & Tí lệ suy dinh dưỡng & \multicolumn{2}{|c|}{3,8} \\
\hline
\end{tabular}

Nhận xét: Triệu chứng chậm tăng cân chiếm $54,7 \%$, viêm phổi $23,6 \%$. đa số trẻ suy tim sớm I,II. Trẻ suy dinh dưỡng chiếm 54,7\%. Chỉ số Z-score trung bình là -2,1 $\pm 3,02$.

Bảng 2: Đặc điểm siêu âm trước mổ

\begin{tabular}{|c|c|c|c|}
\hline \multicolumn{2}{|c|}{ Các đặc điểm trên siêu âm tim } & $\mathbf{n}$ & $\mathbf{\%}$ \\
\hline \multirow{3}{*}{ Vị trí lỗ thông } & Quanh màng & 71 & 67 \\
\cline { 2 - 4 } & Phễu & 30 & 28,3 \\
\cline { 2 - 4 } & Cơ bè & 2 & 1,9 \\
\cline { 2 - 4 } & Buồng nhận & 3 & 2,8 \\
\hline \multirow{2}{*}{$\begin{array}{c}\text { Kích thước } \\
\text { 1ỗ TLT(mm) }\end{array}$} & TB \pm SD & \multicolumn{2}{|c|}{$7,2 \pm 2,4$} \\
\cline { 2 - 4 } & Min - Max & \multicolumn{2}{|c|}{$2-14$} \\
\hline
\end{tabular}

Nhận xét: TLT quanh màng chiếm $67 \%$, phần phễu $28,3 \%$. phần buồng nhận và phần cơ chiếm $2,8 \%$ và $1,9 \%$. Kích thước lỗ thông lớn nhất là $14 \mathrm{~mm}$, bé nhất là $2 \mathrm{~mm}$. Đa số bệnh nhân tăng áp phổi nhẹ vừa. 
Bảng 3. Các thông số trên siêu âm tim trước mổ.

\begin{tabular}{|c|c|c|c|c|}
\hline Giá trị & $\begin{array}{c}\text { Nhỏ nhất } \\
(\mathbf{m m})\end{array}$ & $\begin{array}{c}\text { Lớn nhất } \\
(\mathbf{m m})\end{array}$ & TB \pm SD & Z-score TB \\
\hline ĐK thất trái tâm trương & 16 & 45 & $29,2 \pm 5,9$ & 2,27 \\
\hline ĐK gốc động mạch phổi & 8 & 28 & $14,9 \pm 2,9$ & 3,12 \\
\hline EF \% & 60 & 86 & $70,5 \pm 5,8$ & - \\
\hline
\end{tabular}

Nhận xét: Đường kính thất trái tâm trương và ĐMP đều giãn, Zscore theo cân nặng trung bình đều $>2$. Phân suất tống máu trung bình 70,5 $\pm 5,8 \%$.

\section{Kết quả phẫu thuật sớm và trung hạn}

Bảng 4: Các đặc điểm trong mổ và hậu phẫu

\begin{tabular}{|l|c|c|c|}
\hline \multicolumn{1}{|c|}{ Các đặc điểm } & Lớn nhất & Nhỏ nhất & $\overline{\mathrm{X}} \pm \mathbf{S D}$ \\
\hline Thời gian THNCT (phút) & 31 & 152 & $70,2 \pm 28,0$ \\
\hline Thời gian kẹp ĐMC (phút) & 11 & 117 & $45,7 \pm 26,0$ \\
\hline Kích thước rạch da (cm) & 3,5 & 5 & $4,18 \pm 0,5$ \\
\hline Thời gian thở máy (giờ) & 2 & 52 & $15,7 \pm 10,8$ \\
\hline Thời gian nằm hồi sức (ngày) & 2 & 6 & $3,3 \pm 1,1$ \\
\hline Thời gian nằm viện sau mổ (ngày) & 6 & 20 & $12,4 \pm 5,1$ \\
\hline
\end{tabular}

Nhận xét: Thời gian THNCT trung bình 70,2 $\pm 28,0$, thời gian kẹp ĐMC 45,7 $\pm 26,0$. kích thước rạch da bé nhất $3,5 \mathrm{~cm}$, lớn nhất $5 \mathrm{~cm}$ và trung bình $4,18 \pm 0,5$.

Thời gian thở máy $15,7 \pm 10,8$ giờ, thời gian nằm viện trung bình $12,4 \pm 5,1$, bé nhất 6 ngày, lớn nhất 20 ngày.

Bảng 5: Các biến chứng sau mổ

\begin{tabular}{|c|c|c|}
\hline Tiến chứng lệ & N & \% \\
\hline Shunt tồn lưu & 6 & 5,7 \\
\hline Tràn khí màng phổi & 1 & 0,9 \\
\hline Tràn khí dưới da & 2 & 1,9 \\
\hline Nhiễm trùng vết mổ & 6 & 5,6 \\
\hline Viêm phổi & 5 & 4,7 \\
\hline Loạn nhịp tạm thời & 1 & 0,9 \\
\hline
\end{tabular}

Nhận xét: Tỷ lệ shunt tồn lưu gặp 5,7\%. nhiễm trùng vết mổ gặp ở 6 bệnh nhân, có 2 trường hợp chiếm $1,9 \%$ có tràn khí màng phổi và 1 trường hợp tràn khí dưới da. 6 trường hợp viêm phổi sau mổ và 1 trường hợp loạn nhịp tạm thời sau mổ. 
Bảng 6: ALĐMPTT trên siêu âm sau mổ

\begin{tabular}{|c|c|c|c|c|c|}
\hline \multirow[t]{2}{*}{ TALĐMP } & \multicolumn{2}{|c|}{ Trước mổ } & \multicolumn{2}{|c|}{ Sau mổ } & \multirow[t]{2}{*}{ Giá trị p } \\
\hline & Số lượng & Tỷ lệ (\%) & Số lương & Tỷ lệ (\%) & \\
\hline Bình thường $(\leq 30 \mathrm{mmHg})$ & 41 & 38,7 & 74 & 69,8 & 0,000 \\
\hline Nhẹ - vừa $(30-50 \mathrm{mmHg})$ & 51 & 48,1 & 31 & 29,3 & 0,024 \\
\hline Nặng (50- 70mmHg) & 12 & 11,3 & 1 & 0,9 & 0,000 \\
\hline Rất nặng (>70mmHg) & 2 & 1,9 & 0 & 0 & 0,002 \\
\hline
\end{tabular}

Nhận xét: Có sự thay đổi đáng kể về ALĐMPTT sau mổ. Đa số ALĐMP về bình thường.

Bảng 7: Tình trang suy tim và suy dinh duõong khi khám lại

\begin{tabular}{|c|c|c|c|c|c|c|}
\hline \multirow{2}{*}{\multicolumn{2}{|c|}{ Đặc điểm Thời điểm }} & \multicolumn{2}{|c|}{ Trước mổ } & \multicolumn{2}{|c|}{ Khi khám lại } & \multirow{3}{*}{$\begin{array}{c}\mathbf{p} \\
<0,001\end{array}$} \\
\hline & & \multirow{2}{*}{$\begin{array}{l}\mathbf{n} \\
48\end{array}$} & \multirow{2}{*}{$\begin{array}{c}\% \\
45,3\end{array}$} & \multirow{2}{*}{$\begin{array}{c}\mathbf{n} \\
87\end{array}$} & \multirow{2}{*}{$\begin{array}{c}\% \\
94,6\end{array}$} & \\
\hline \multirow{2}{*}{ Suy tim } & Độ I & & & & & \\
\hline & Độ II-III & 58 & 54,7 & 5 & 5,4 & $<0,001$ \\
\hline \multirow{2}{*}{$\begin{array}{c}\text { Suy dinh } \\
\text { dưỡng }\end{array}$} & Z-score cân nặng & \multicolumn{2}{|c|}{$-2,1 \pm 3,02$} & \multicolumn{2}{|c|}{$-1,5 \pm 1,7$} & $<0,05$ \\
\hline & Tỉ lệ suy dinh dưỡng (\%) & \multicolumn{2}{|c|}{54,7} & \multicolumn{2}{|c|}{20,6} & $<0,05$ \\
\hline
\end{tabular}

Nhận xét: Tỷ lệ bệnh nhân suy tim độ II-III giảm rõ rệt so với thời điểm trước mổ $(\mathrm{p}<0,05)$

Tỷ lệ bệnh nhân không suy dinh dưỡng tăng cao so với thời điểm trước mổ $(\mathrm{p}<0,05)$

\section{BÀN LUẬN}

\section{1. Đặc điểm chung:}

Tuổi: độ tuổi trung bình là $1,1 \pm 1,7$ tuổi $(13,3 \pm 20,7$ tháng tuổi $)$, trong đó thấp nhất là 1 tháng và cao nhất là 10 tuổi. So sánh với các nghiên cứu khác, Hong Liu và cộng sự (2018) về phẫu thuật ít xâm lấn vá TLT ở 200 trẻ sơ sinh và trẻ nhỏ thì có độ tuổi trung bình là 24,38 tháng, trong đó thấp nhất là $5^{\text {th }}$ và cao nhất là 55th [4]. Nghiên cứu Wang và cộng sự (2010) trên 274 bệnh nhân vá TLT qua đường mở ngực phải từ năm 2001 đến 2008 có độ tuổi trung bình là 10,5 $\pm 8,9$ tuổi [5]. Giới:nam giới chiếm tỉ lệ $57 \%$, nữ giới chiếm tỉ lệ $43 \%$. Tỉ lệ Nam/Nữ là 1,3.Kết quả này có tỉ lệ tương đồng với nghiên cứu khác như theo Hong Liu (2018) thì tỉ lệ nam là $52 \%$, nữ là $48 \%$ [4]. Cân nặng: Cân nặng trung bình trong nghiên cứu là $7,7 \pm 4,1 \mathrm{~kg}$. Theo Hong Liu (2018) thì cân nặng trung bình là 13,16 kg [4], nghiên cứu của Zhi Nuan Hong (2018) về nhóm phẫu thuật vá TLT ít xâm lấn qua đường ngưc phải thì cân nặng trung bình là $8,3 \pm 2,3 \mathrm{~kg}$, độ tuổi trung bình là $1,3 \pm 1,2$ tuổi [6].

So với các nghiên cứu khác về ít xâm lấn thì nghiên cứu chúng tôi có độ tuổi và cân nặng trung bình thấp hơn. Điều này cho thấy những năm gần đây khả năng phẫu thuật TLT sớm giúp cho trẻ có cuộc sống bình thường và đang ngày càng tiến bộ, bắt kịp các trung tâm phẫu thuật tim mạch trên thế giới. Không những thế, việc áp dụng phương pháp ít xâm lấn đường ngực phải vá TLT tuy vấp phải nhiều khó khăn nhưng chúng tôi cũng đã cố gắng triển khai và dần phát triển ngay trên những bệnh nhân có độ tuổi và cân nặng bé 
nhất so với các nghiên cứu trên thế giới. Điều đó đã đem lại nhiều hiệu quả cũng như sự hài lòng tốt nhất cho bệnh nhân và người nhà.

\section{2. Đặc điểm về lâm sàng và cận lâm sàng}

Triệu chứng lâm sàng: Ở trẻ em tỉ lệ vào viện phẫu thuật theo hẹn do phát hiện tình cờ chiếm đến $57,7 \%$ chủ yếu là phát hiện qua khám sàng lọc, các triệu chứng chủ yếu là viêm phế quản phổi chiếm $23,6 \%$, mệt mỏi, bú kém chiếm $17,9 \%$ và triệu chứng chậm tăng cân chiếm đa số với $54,7 \%$. Đa số bệnh nhân suy tim giai đoạn sớm I,II chiếm $96,2 \%$. Kết quả này tương đồng với nghiên cứu Lê Khắc Mạnh (2018) khi đánh giá về phẫu thuật ít xâm lấn chung vá TLT khi triệu đa số bệnh nhân phát hiện tình cờ chiếm $62,2 \%$, viêm phổi $13,5 \%$ và $100 \%$ bệnh nhân suy tim độ I,II [7]. Kết quả chúng tôi có $54,7 \%$ suy dinh dưỡng vừa - nặng trước mổ, đây là một dấu hiệu quan trọng được nhiều tác giả quan tâm, là hậu quả của quá trình dinh dưỡng kém kéo dài do trẻ khó thở, viêm phổi tái diễn, bú kém và hấp thu không đầy đủ. Vaidyanathan $\mathrm{B}$ (2002) cho rằng đối với các nước đang phát triển (trong đó có Việt nam) thì tình trạng nghèo đói và hạn chế về kiến thức dinh dưỡng làm trầm trọng thêm dấu hiệu chậm phát triển của trẻ mắc TLT lỗ lớn. Tuy nhiên ông chỉ ra rằng tình trạng suy dinh dưỡng không làm tăng tỉ lệ tử vong sau mổ và phẫu thuật vá TLT lỗ lớn không nên bị trì hoãn bởi các nguyên nhân trên [8].

Đặc điểm trên siêu âm truớc mổ: Về vị trí TLT trên siêu âm tim (Bảng 2) phần lớn là TLT quanh màng $(67 \%)$, phần phễu $(28,3 \%)$, phần buồng nhận $(2,8 \%)$, phần cơ bè $(1,9 \%)$. Theo nghiên cứu của Dixit và cộng sự (2020) về phẫu thuật vá TLT ít xâm lấn đường ngực phải với cannula trung tâm ở 54 bệnh nhân tại Ấn Độ thì tỉ lệ quanh màng là $87 \%$, phần phễu $3,7 \%$, cơ chiếm $3,7 \%$ và buồng nhận chiếm $5,6 \%$ [9]. Kết quả này tương đồng với nghiên cứu chúng tôi. Đường kính lỗ TLT trong nghiên cứu của chúng tôi trên siêu âm: kích thước nhỏ nhất là $2 \mathrm{~mm}$, kích thước lỗ thông lớn nhất là $15 \mathrm{~mm}$, với đường kính trung bình là $6,9 \pm 2,8 \mathrm{~mm}$. Kết quả này phù hợp với các nghiên cứu của Nguyễn Công Hựu năm 2005 với kích thước trung bình $7,10 \pm 6,16 \mathrm{~mm}$ [10], nghiên cứu của Liao 2017 với kích thước trung bình $7.9 \pm 4.4 \mathrm{~mm}[11]$. Hay trong nghiên cứu của Liu Huagang (2017) trên 3 nhóm bệnh nhân phẫu thuật TLT thì nhóm đi đường ngực Phải có kích thước 7,41 $\pm 2,63 \mathrm{~mm}$ [12].

Sự thay đổi kích thước các buồng tim được ghi nhận trên siêu âm - Doppler tim: Đường kính thất trái tâm trương và đường kính gốc ĐMP giãn to (Z-score trung bình lần lượt là 2,27 và 3,12 ) (Bảng 3). Những dấu hiệu trên đã phản ánh trung thực tình trạng TALĐMP ở nhóm BN được nghiên cứu. BN bị TLT ban đầu biểu hiện suy tim trái thể hiện trên siêu âm là đường kính thất trái cuối tâm trương giãn, do shunt T-P gây máu lên phổi nhiều => máu về thất trái nhiều trong thời kì tâm trương => thất trái sẽ giãn theo cơ chế Frank - Starling.

\section{3. Đặc điểm trong phẫu thuật:}

\section{Quy trình phẫu thuật:}

- Mở ngực: rạch da 3 - $5 \mathrm{~cm}$ tương ứng khoang liên sườn $\mathrm{V}$ đường trước ngực phải. Qua các lớp giải phẫu vào khoang màng phổi phải qua khoang liên sườn IV. Mở dọc màng ngoài tim phía trước dây thần kinh hoành.

- Heparin toàn thân. Thiết lập hệ thống THNCT cơ thể trực tiếp qua phẫu trường.

- Đặt lắc TM chủ trên và dưới, đặt kim truyền dịch bảo vệ cơ tim qua gốc ĐMC. Đặt clamp ĐMC trực tiếp qua trường mổ.

- Bơm bảo vệ cơ tim bằng dung dịch Custadiol qua gốc ĐMC, hạ nhiệt độ tới $32^{\circ} \mathrm{C}$. 
- Mở tim đánh giá mức độ tổn thương và tiến hành vá lỗ thông. Kĩ thuật vá thường khâu vắt có thể kết hợp mũi rời tăng cường, chỉ prolene 6/0. Khâu đóng đường mở tim, thả cặp tĩnh mạch chủ, phục hồi thông khí phổi. Đuổi khí khỏi các buồng tim, thả cặp ĐMC.

- Tim đập trở lại, tiếp tục duy trì tuần hoàn ngoài cơ thể để hỗ trợ tim. Hạ dần lưu lượng rồi

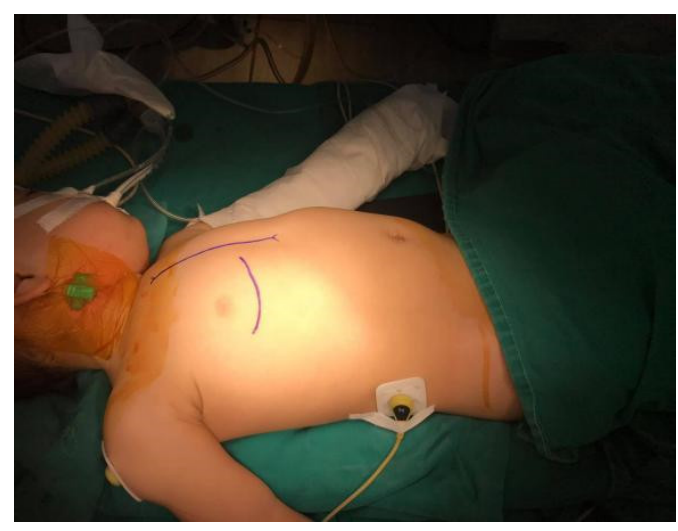

Anh 1: Vết mổ dụ kiến

\section{Đặc điểm trong phẫu thuật:}

Thời gian tuần hoàn ngoài cơ thể trung bình là $70,2 \pm 28$ phút, ngắn nhất là 31 phút và dài nhất là 152 phút. thời gian cặp ĐMC ngắn nhất là 11 phút, dài nhất là 117 phút, trung bình là $45,7 \pm 26$ phút. So với thế giới như nghiên cứu của Liao thì thời gian THNCT là 102,5 $\pm 13,6$ phút, thời gian cặp chủ trung bình là $54,6 \pm 6,9$ phút [11]. Nghiên cứu của Wang thì thời gian chạy máy tim phổi nhân tạo trung bình là $61,6 \pm 27,8$ phút, thời gian cặp chủ trung bình là $33,4 \pm 20,8$ phút [5]. Tác giả Dixit thì thời gian kẹp ĐMC là 38,51 $\pm 13,08$ phút [9]. Kết quả trung bình của chúng tôi có sự chênh lệch không đáng kể so với các nghiên cứu trên.

Kích thước thước vết mổ trung bình trong nghiên cứu của chúng tôi là $4,18 \pm 0,5 \mathrm{~cm}$, nhỏ nhất là $3,5 \mathrm{~cm}$ và dài nhất là $5 \mathrm{~cm}$. So với nghiên cứu của Liao là $5,1 \pm 0,6 \mathrm{~cm}$ [11], nghiên cứu của Wang 7,2 $\pm 2,9 \mathrm{~cm}$ [5], Nghiên cứu của Dixit là ngừng tuần hoàn ngoài cơ thể. Rút các ống khỏi tĩnh mạch chủ và ĐMC. Trung hoà chống đông Heparine bằng Protamine.

- Cầm máu, đặt điện cực. Đặt dẫn lưu màng tim, đóng màng tim. Cầm máu thành ngực, đặt dẫn lưu màng phổi và dẫn lưu màng tim.

- Đóng thành ngực và các lớp giải phẫu.

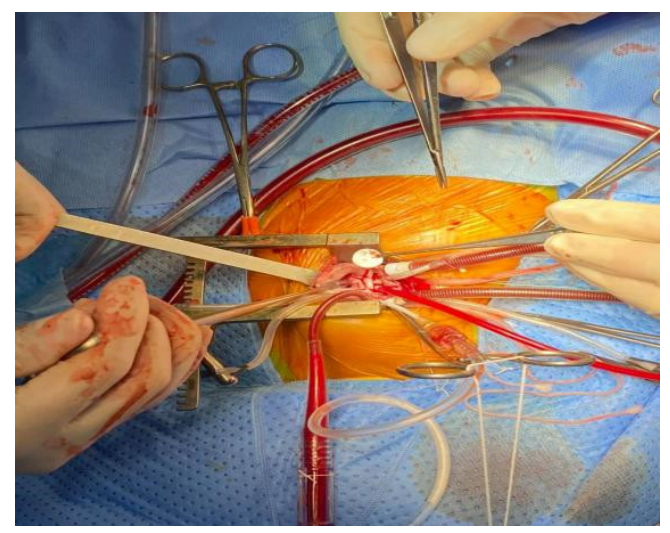

Anh 2: Vá TLT bằng miếng vá nhân tạo

$7,16 \pm 2,08 \mathrm{~cm}$, với nhỏ nhất là 5 và lớn nhất là 9 $\mathrm{cm}$ [9]. So với kết quả trên thì vết mổ chúng tôi nhỏ hơn.

Nghiên cứu chúng tôi, thời gian thở máy trung bình là $15,7 \pm 10,8$ giờ, trong đó ngắn nhất là 2 giờ và dài nhất là 52 giờ, thời gian nằm hồi sức là $3,3 \pm 1,1$ ngày, thời gian nằm viện sau mổ là $12,4 \pm 5,1$ ngày, ngắn nhất là 6 ngày và dài nhất là 20 ngày. Trong nghiên cứu của Wang thời gian nằm viện sau mổ là $4,9 \pm 2,6$ ngày [5]. theo Dixit thì thời gian nằm hồi sức là $2,13 \pm 1,32$ ngày, thời gian nằm viện $4,92 \pm 1,8$ ngày [9]. Theo nghiên cứu của Hong Liu (2018) thời gian thở máy trung bình là $16,6 \pm 4,4$ giờ, thời gian nằm hồi sức là $21,7 \pm 5,2$ giờ, thời gian nằm viện sau mổ là 9,2 $\pm 3,2$ ngày [6]. Thời gian nằm viện sau phẫu thuật của chúng tôi dài hơn so với các tác giả trên do chúng tôi theo dõi bệnh nhân tới lúc ổn định hẳn, có thể cắt chỉ trước khi ra viện. Tuy nhiên thời gian thở máy của chúng tôi tương đồng, 
điều này cho thấy phương pháp phẫu thuật ít xâm lấn đường ngực phải ngoài mang lại lợi ích về thẩm mỹ còn thấy sự hồi phục nhanh sau mổ.

\section{Kết quả phẫu thuật}

\section{Biến chúng sau mổ}

Có 1 trường hợp tràn khí màng phổi, 2 trường hợp tràn khí dưới da, 5 trường hợp viêm phổi, 6 trường hợp nhiễm trùng vết mổ và 1 trường hợp loạn nhịp tạm thời sau mổ. Theo tác giả ZhiNuan Hong (2018) thì nghiên cứu trên 62 bệnh nhân thuộc nhóm đường mở ngực phải có 7 bệnh nhân viêm phổi, 3 bệnh nhân tràn khí màng phổi, 2 bệnh nhân tràn khí dưới da và 6 bệnh nhân có rối loạn nhịp thoáng qua [6], kết quả này phù hợp nghiên cứu chúng tôi. Có 6 trường hợp còn shunt tồn lưu sau mổ chiếm $5,7 \%$, tất cả đều là shunt tồn lưu nhỏ $<2 \mathrm{~mm}$. Tỉ lệ shunt tồn lưu cũng rất dao động trong nhiều nghiên cứu từ $10-30 \%$. Nguyễn Quang Minh (21,8\%) [13], Cũng theo Maartje Schipper (2017), tỉ lệ shunt tồn lưu trong nghiên cứu của ông là $71 \%$ và đều là shunt rất nhỏ, hầu hết đều tự đóng sau trung bình 3,1 năm [14]. Dodge-Khatami (2007) nghiên cứu trên 198 $\mathrm{BN}$ có shunt tồn lưu sau mổ đã chỉ ra rằng $83 \%$ shunt tồn lưu có kích thước $\leq 2 \mathrm{~mm}$ sẽ tự đóng và theo ông những trường hợp còn shunt tồn lưu nhưng không ảnh hướng tới huyết động thì không cần can thiệp hay điều trị gì thêm, cũng không có nguy cơ bị viêm nội tâm mạc [15]

Thay đổi siêu âm sau mổ: Có sự thay đổi rõ rệt về ALĐMP sau mổ với đa số bệnh nhân sau mổ có ALĐMP ở mức bình thường dưới $30 \mathrm{mmHg}$ chiếm $69,8 \%$ tỉ lệ bệnh nhân có ALĐMP nhẹ -vừa chiếm 29,3\%.

Kết quả khám lại: Trong nghiên cứu này thì tỉ lệ shunt tồn lưu sau mổ là 6 trường hợp $(5,7 \%)$ với kích thước $<2 \mathrm{~mm}$. Tất cả các trường hợp đều đóng lại sau khi tái khám, trong đó có 4 trường hợp lỗ thông tự đóng sau 3 tháng, 2 trường hợp còn lại thì đóng sau 6 tháng. Tỉ lệ suy tim ROSS II chỉ còn $5,4 \%$ so với trước mổ là $54,9 \%$. Đa số các bệnh nhân đều trề cuộc sống bình thường, các triệu chứng lâm sàng cải thiện rõ rệt như viêm phổi, mệt mỏi hay khó thở.

Tình trạng dinh dưỡng của BN cũng thấy sự thay đổi rất rõ rệt. Chỉ số Z-score theo cân nặng trung bình là $-1,5 \pm 1,7$. Đa số các trẻ đã không còn tình trạng suy dinh dưỡng $(79,4 \%)$ tại thời điểm khám lại, chỉ còn $20,6 \%$ trẻ còn suy dinh dưỡng mức độ vừa - nặng, đó đa phần là những trẻ đẻ non, cân nặng lúc sinh thấp hơn so với tuổi thai và nhóm trẻ lớn đã SDD trong 1 thời gian dài trước đó. 3-6 tháng sau mổ đều tăng cân nhưng tính Zscore cân nặng theo tuổi vẫn nằm trong nhóm suy dinh dưỡng, để đánh giá tình trạng dinh dưỡng của nhóm trẻ này cần có thêm thời gian để theo dõi. Vaidyanathan $B$ và cộng sự (2002) đã tiến hành phẫu thuật cho 100 trẻ có TLT lỗ lớn với độ tuổi trung bình $7.4 \pm 3.3$ tháng, Zscore cân nặng theo tuổi trung bình: $-2.8 \pm 1.3$ cũng cho kết quả rất khả quan [8].

\section{KẾT LUẬN}

Phẫu thuật ít xâm lấn vá TLT qua đường ngực phải của chúng tôi cho kết quả tương đương so với các nghiên cứu khác trên thế giới. Đặc điểm nổi bật của phương pháp này mang lại là tính thẩm mỹ, giảm mức độ đau sau mổ và tránh được các nguy cơ xảy ra khi phẫu thuật theo phương pháp kinh điển theo đường dọc xương ức mà vẫn mang lại tính an toàn và hiệu quả. Mặc dù gặp nhiều khó khăn ngay từ lúc mới triển khai, tuy nhiên chúng tôi cũng rút được nhiều kinh nghiệm và dần hoàn thiện hơn phương pháp này có thể được triển khai rộng rãi, hướng đến việc phẫu thuật thường quy để mang lại lợi ích cho các bệnh nhân. 


\section{TÀI LIỆU THAM KHẢO}

1. Nguyễn Lân Việt (1996), "Thông liên thất", Thực hành tim mạch học, Nhà xuất bản $\mathrm{y}$ học, tr. 120-130.

2. Fyler D.C, John Keane, và James Lock (2006), "Ventricular septal defects", Nadas pediatric cardiology, Saunders, pp. 435-437.

3. Đặng Quang Huy và Nguyễn Thị Hảo, Nguyễn Công Hựu, Lê Ngọc Thành, (2015), "Phẫu thuật tim hở ít xâm lấn bằng đường mổ nhỏ nửa dưới xương ức trong vá thông liên thất", Tạp chí Y học Việt nam. pp, 2-8.

4. Hong Liu, Feng-xia Lu, Jie Zhuo et al (2018), "Minimally invasive perventricular versus open surgical ventricular septal defect closure in infants and children: a randomised clinical trial". pp, 1-9. (doi:10.1136/heartjnl-2017-312793)

5. Wang $\mathrm{Q}$ và Zhang $\mathrm{J} \mathrm{Li} \mathrm{Q}, \mathrm{Wu} \mathrm{Z}$, Zhou Q, Wang DJ (2010), "Ventricular septal defects closure using a minimal right vertical infraaxillary thoracotomy: seven-year experience in 274 patients", Ann Thorac Surg. 89(2), 552-555.

6. Zhi-Nuan Hong, Ze-Wei Lin, Qiang Chen and et al (2018), "Surgical repair via submammary thoracotomy, right axillary thoracotomy and median sternotomy for ventricular septal defects", J Cardiothorac Surg. 13(47).

7. Lê Khắc Mạnh, Lê Ngọc Thành (2018). “ Kết quả phẫu thuật tim hở it xâm lấn tại trung tâm tim mạch Bệnh viện E'. Luận văn thạc sỹ Y học, Đại Học Y Hà Nội.

8. Vaidyanathan B, Rao S. G, Roth S. J and et al (2002), "Outcome of ventricular septal defect repair in a developing country", The Journal of pediatrics. 140(6), pp. 736-741.

9. Dixit, Anil Sharma, Jaikishan
Suthar,Vikram Wattit, Mohit (2021), "Repair of ventricular septal defect through anterolateral thoracotomy with central cannulation: our experience". Indian Association of Cardiovascular-Thoracic Surgeons, pp. 476-582.

10. Nguyễn Công Hựu và Lê Ngọc Thành (2005), "Nghiên cúu đặc điểm lâm sàng, cận lâm sàng và kết quả điều trị phẫu thuật thông liên thất phần phễu tại bệnh viện Việt Đức", Luận văn Thạc sỹ Y học, Đại học Y Hà Nội.

11. Liao $Y$ và $Z$ hu $S$ Long $X, T u J$, Wen $H$, Xu J, Wu Y (2017), "Minimally access via left anterior mini-thoracotomy for repair of adult subarterial ventricular septal defects", $J$ Cardiothorac Surg. 12(1), 48.

12. Liu Huagang, Wang Zhiwei, PhD, Xia Jun and et al (2017), "Evaluation of Different Minimally 3 Invasive Techniques in Surgical Treatment 4 for Ventricular Septal Defect", Cardiac Society of Australia and New Zealand, pp. 365-370

13. Nguyễn Quang Minh (2019), "Đặc điểm lâm sàng, cận lâm sàng và đánh giá kết quả điều trị phẫu thuật vá thông liên thất ở trẻ có cân nặng $\leq 5 \mathrm{~kg}$ tại trung tâm tim mạch bệnh viện E”, Luận văn Thạc sĩ Y học, Đại học Y Hà Nội.

14. Schipper M., Slieker M.G., Schoof P.H. và cộng sự. (2017). "Surgical Repair of Ventricular Septal Defect; Contemporary Results and Risk Factors for a Complicated Course". Pediatr Cardiol, 38(2), 264-270

15. Dodge-Khatami A., Knirsch W., Tomaske M. and et al. (2007). "Spontaneous closure of small residual ventricular septal defects after surgical repair". Ann Thorac Surg, 83(3), 902-905. 